\author{
Berend DENKENA ${ }^{1}$ \\ Benjamin BERGMANN ${ }^{1}$ \\ Miriam HANDRUP ${ }^{*}$ \\ Christopher SCHMIDT ${ }^{1}$
}

\title{
CONTROLLED TURNING PROCESS FOR THE PRODUCTION OF FRICTION-REDUCED CYLINDER LINERS WITH A DEFINED FREE-FORM GEOMETRY
}

\begin{abstract}
Friction in the piston-cylinder system of combustion engines has a great influence on fuel consumption. To reduce the friction of combustion engines, free-form cylinder liners and microstructured cylinder liners have proven to be advantageous. However, the combination of both processes is not industrially realized today because of an increased manufacturing effort due to a higher number of process steps. To save resources in form of honing oil in the production, the free-form can be machined by a dry turning process instead of form honing. A combination with the microstructuring process in a single manufacturing step would furthermore reduce nonproductive time. This paper presents a piezo-actuated hybrid tool that can carry out both processes. The tool wear and the behavior during free-form fine machining of cylinder liners are investigated. A process control system is introduced that controls the cylinder liner geometry by adapting the process parameters during free-form turning.
\end{abstract}

\section{INTRODUCTION}

In today's society, automobility is an important factor. The number of passenger cars has constantly risen in the last decade [1]. Despite the goal of the UN of limiting global warming to well below $2 \mathrm{~K}$ compared to pre-industrial times [2] and increasing sales of electric cars the percentage of sold passenger cars with combustion engines in Europe in $1^{\text {st }}$ quarter 2020 was still around $80 \%$ [3]. In view of climate change, it is still necessary to reduce the fuel consumption of combustion engines and the energy demand of their production [4]. Since the piston-liner system has a large impact on the resource-efficiency, different approaches were investigated to decrease the friction between the piston and the liner. The surface of cylinder liners is finished by honing which is the most commonly used process in the automotive and commercial vehicle industry $[5,6]$. The honed surface can

\footnotetext{
${ }^{1}$ Institute of Production Engineering and Machine Tools, Leibniz Universität Hannover, Germany

*E-mail: handrup@ifw.uni-hannover.de https://doi.org/10.36897/jme/139207
} 
additionally be coated with thermally sprayed coatings to improve the wear behavior and the thermal conductivity, which reduces the inner friction of the piston-liner system [7]. Another approach is to adapt the liner's surface by the application of defined micro dimples [6]. Micro dimples can be machined with a fly cutting tool [8] or with an active tool e.g. developed by Dahlmann and Denkena [9]. Similar to the grooves of a honed surface, the micro dimples provide a volume for lubricant. But, in contrast to the honing grooves, the micro dimples are self-contained and thus prevent lubricant from being pushed out of the contact zone between liner and piston ring $[10,11]$. This effect can be used to prevent the lubricant film from failing in the areas with small relative speeds - the Top Dead Center (TDC) and the Bottom Dead Center (BDC).

Previous investigations using honed cylinder liners that were equipped with a suitable arrangement of micro dimples proved the potential for friction reduction [12]. The results shown in Fig. 1 are from a Floating-Liner (FL) test engine capable of measuring the crank angle resolved friction force between piston and liner. The friction behavior changes differently depending on the piston's position in the liner. However, the friction force of the microstructured liner is on a noticeably smaller level.



Fig. 1. Measured friction force for different cylinder liner's surfaces [13]

Another approach to reduce the friction within the piston-liner system is the adaption of the cylinder liner's geometry deviating from a cylindrical geometry. Analogous to the friction forces given in Fig. 1, the thermal and mechanical load on the liner varies over its height. This leads to a geometrical deviation in different geometrical orders by expansion or constriction. Examples of this simulated geometrical deviation are given in Fig. 2 . The geometrical deviations change depending on the liner's height and also on its circumferential position.

As a consequence of this deviation, the fitting between piston and liner changes during operation and may lead to a gap above or below the tolerance of dimension. A liner constriction causes an overlap leading to higher friction between piston and liner. Whereas the expansion of the liner enlarges the gap between liner and piston leading to a leakage of the combustion chamber and noise emissions.

The approach to reduce these two possible errors is to anticipate the liner's geometrical deviation by form honing [14]. This can be done by a reduction or increase of the liner's diameter depending on its height. A variable liner diameter as a function of the circumferential position is also possible $[15,16]$. However, form honing processes are energy-intensive 
due to the necessity of honing oil and prolong the process chain of cylinder liners. A geometrical deviation of a cylinder liner can also be realized by adapted turning processes [17]. These processes use a piezo-actuated defined deflection of the tool to control the cutting depth and thus the generated workpiece geometry. This approach is used to generate the cylinder's free-form. With the increasing performance of cutting materials, turning processes can be performed without lubricant which is an advantage compared to honing processes that require high amounts of lubricant. As shown, there has been no method of producing cylinder liners with a free-form geometry and microstructures in a single manufacturing step. To reduce non-productive time and positioning errors due to reclamping between the free-form turning and microstructuring process, a new hybrid tool was developed which can carry out both processes.


Fig. 2. Geometrical deviation in different geometrical orders

This paper focuses on the development of the turning process for the production of friction-reduced cylinder liners with a defined free-form geometry. This process will substitute the rough form honing process in the process chain. Subsequently, a finish form honing will be applied to generate the final surface quality. First, the design of the hybrid tool is introduced. The process parameters' influence on the tool wear and the influence of the fine machining process on the workpiece's surface topography are investigated. Last, the control of the free-form turning process is developed and the first tests are carried out.

\section{HYBRID TOOL DESIGN}

The hybrid tool was designed to perform both the non-circular turning process and the microstructuring process. The intended process sequence is to perform the turning-process followed by the microstructuring process. As the two processes require different process characteristics and tool-geometries, two cutting inserts are mounted on the tool (see Fig. 3). They are each radially deflected with piezo actuators that have a maximum stroke $\Delta h_{\max }=60 \mu \mathrm{m}$ at a static voltage of $U_{\max , \text { static }}=1,000 \mathrm{~V}$. Changing the voltage from a static 
to a dynamic voltage, the piezo actuator is charged and discharged following the applied voltage. The charging and discharging speed is limited by the capacity of the actuator. Thus, the actuator's maximum deflection decreases by increasing the dynamic voltage frequency. With high power analog switching amplifiers, structuring frequencies $f_{\text {struct }}$ of up to $2,000 \mathrm{~Hz}$ are achieved.

The piezo-actuators are arranged in an axial order. They are aligned in radial direction. The objective of the unroundness of the cylinder liner is around $\Delta r=30-40 \mu \mathrm{m}$. The micro dimples are aimed to have a depth of $20 \mu \mathrm{m}$. However, since up to $40 \mu \mathrm{m}$ of material is removed during the subsequent finish honing process, the micro dimples need to be machined with a depth of $60 \mu \mathrm{m}$. To use the limited stroke length of the piezo actuator solely for microstructuring, a constant distance between the cutting insert of the microstructuring unit and the workpiece surface must be established. Therefore, the microstructuring unit is equipped with a roller bearing with which it is pressed against the liner's inner surface by a pneumatic auxiliary drive. Thus, the piezo actuator stroke can solely be used for machining the micro dimples and does not need to follow the unroundness of the cylinder liner.
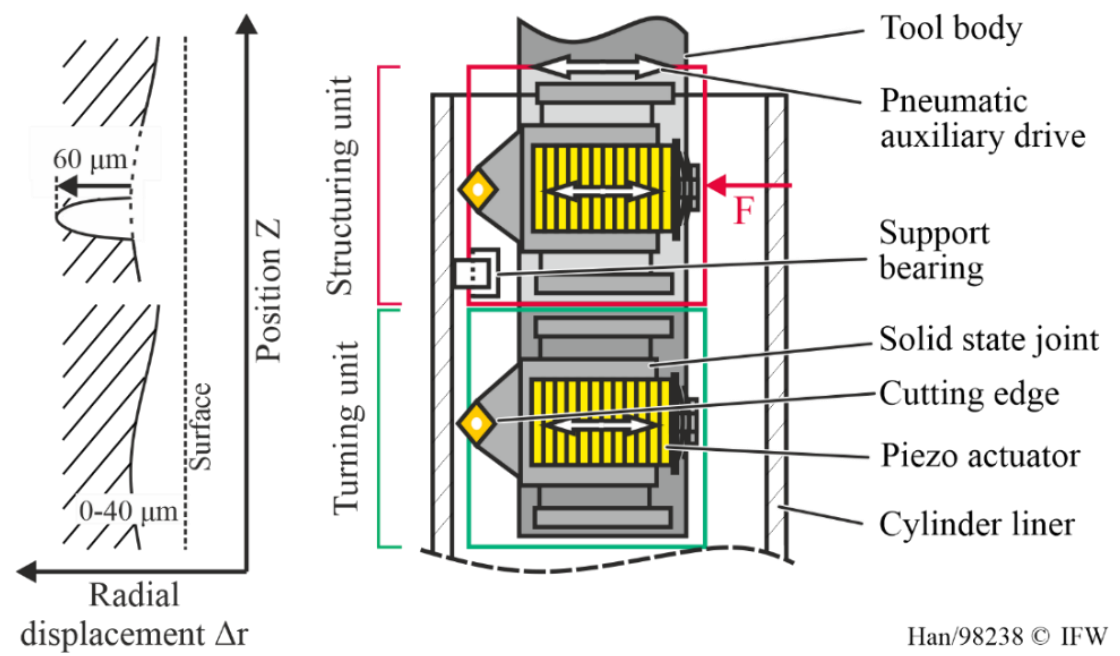

Fig. 3. Tool concept

Both piezo actuators have integrated strain gauges in a full-bridge configuration and Pt100 resistance thermometers to monitor the stroke of the piezo actuator and their temperature. Besides, acceleration sensors are equipped on each unit to monitor the process. A confocal sensor between the two units measures the machined cylinder liner geometry and controls the voltage of the piezo actuators to minimize errors in the process chain.

The hybrid tool is set up in the lathe (see Fig. 4). It is clamped into the turret with a standard VDI 40 tool holder. The cylinder liners are clamped in the chuck of the main spindle. The sequence of the process is as follows: First, the turning unit of the tool is used to machine the non-circular cylinder liner in the negative $Z$-axis direction. When pulling the hybrid tool out of the cylinder liner the confocal sensor measures the geometry of the liner. In the next step, the pneumatic auxiliary drive is triggered and the structuring unit is pressed against the inner surface of the cylinder liner. 




Fig. 4. Set up of hybrid tool in the machine

When moving the hybrid tool in a negative $Z$-axis direction the cylinder liner is microstructured and when pulling the hybrid tool out of the cylinder a microstructure is measured with the confocal sensor. While unclamping the workpiece by the worker, the measurement results are visually prepared. Based on the measurement the quality of the cylinder liner can be evaluated and the process parameters are adjusted for the next workpiece.

\section{INFLUENCE ON TOOL WEAR}

In serial production, cylinder liners are produced in high volumes. Consequently, the new process approach must be capable of high tool life and high dimensional accuracy both in rough and fine machining. Therefore, the process parameters' influence on the tool wear during rough machining is examined. These investigations are performed to avoid sudden cutting edge breakouts decreasing the process reliability and thus its productivity. Subsequently, the influence of the fine machining process on the surface topography is examined.

Experimental investigations are carried out on a CTX beta 800 4A lathe. The cutting material used is Cubic boron nitride $(\mathrm{CBN})$, as it offers a higher toughness compared to cutting ceramics and higher hardness compared to cemented carbide. The cutting inserts being used have a corner radius of $r_{\varepsilon}=0.4 \mathrm{~mm}$.

As an example of the investigated wear behavior during rough machining Fig. 5 shows the progression of the maximum width of flank wear land $V B_{B \max }$ during the circular turning process with a depth of cut of $a_{p}=0.5$ and $a_{p}=0.25 \mathrm{~mm}$. The experiments were conducted once without repetition. Machining is performed without cooling lubricant and the abort criterion is set to $V B_{B \max }=0.4 \mathrm{~mm}$, which is the thickness of the tool's CBN inlay. As can be seen from the wear curve, the process with a higher depth of cut ( $a_{p}=0.5 \mathrm{~mm}$ ) enables higher maximum material removal $V_{W}$ in comparison to a reduced depth of cut $\left(a_{p}=0.25 \mathrm{~mm}\right)$. The highest material removal $V_{W}$ is achieved with a depth of cut of $a_{p}=0.5 \mathrm{~mm}$ at a cutting speed of $v_{c}=600 \mathrm{~m} / \mathrm{min}$. The comparison between the different cutting depths shows that the process with a lower depth of cut does not have a great dependence on the cutting speed $v_{c}$. However, in contrast to the findings at a depth of cut of $a_{p}=0.5 \mathrm{~mm}$, the absence of cutting 
speed dependency might result from random wear behavior in the experiments. Wear experiments for both depths of cut need to be repeated as here only one cutting tool was investigated without repetition. The process performed at a depth of cut of $a_{p}=0.5 \mathrm{~mm}$ shows a wide range in realized material removal $V_{W}$ depending on the cutting speed. The two wear curves at $v_{c}=600$ and $900 \mathrm{~m} / \mathrm{min}$ show extensive continuous sections without a strong increase in wear, which is important for process reliability. In contrast, an increased cutting speed of $v_{c}=1,200 \mathrm{~m} / \mathrm{min}$ reduces the tool life and thus decreases the achieved material removal exceedingly. Accordingly, a suitable cutting speed $v_{c}$ is required for a high depth of cut $\left(a_{p}=0.5 \mathrm{~mm}\right)$ to outperform the process carried out at a low depth of cut $\left(a_{p}=0.25 \mathrm{~mm}\right)$ concerning tool life.

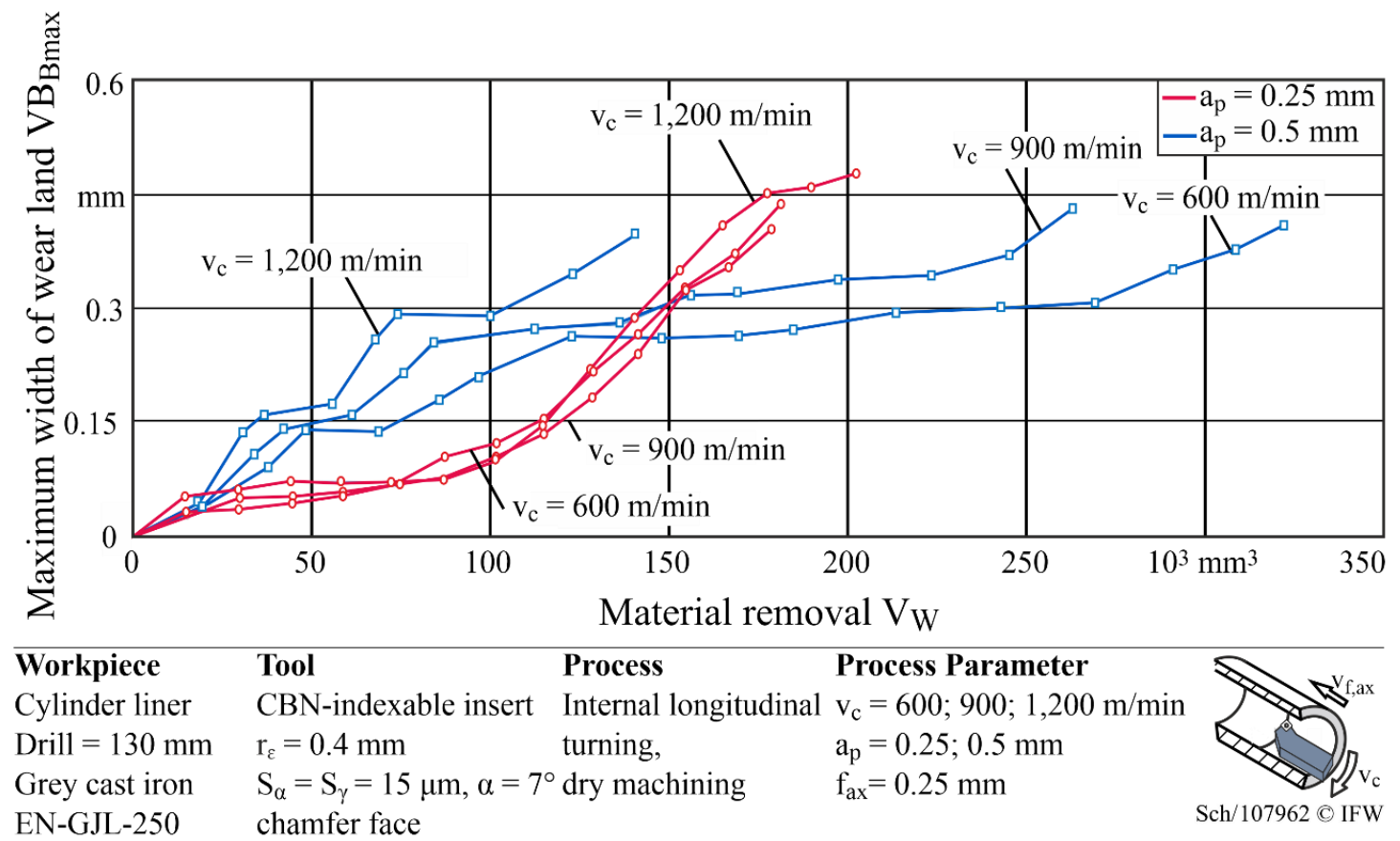

Fig. 5. Wear progression of the CBN-cutting insert in dry machining of grey cast iron cylinder liners

The results show that higher cutting speeds shorten the tool life. The reason can be traced back to a higher thermal load on the tool due to a higher heat flux density and high material forming speed. The tribochemical interaction between tool and workpiece is another important factor. The detailed influence of the process parameters on the tool wear appearance will be discussed in the following.

The wear appearance of the cutting inserts that cut with $a_{p}=0.5 \mathrm{~mm}$ is investigated as it shows the highest influence of the cutting speed. Microscopic images of the worn tools are presented in Fig. 6. All tools were used until their maximum width of flank wear land $V B_{B \max }$ reached $400 \mu \mathrm{m}$. Distinctive flank wear occurs in turning of grey cast iron EN-GJL-250. Uniform abrasive flank wear and adhesion were observed by scanning electron microscopy (SEM). As shown in the SEM-microscopy the abrasive flank wear appears to be slightly uneven at cutting speeds of $v_{c}=600$ and $900 \mathrm{~m} / \mathrm{min}$ compared to the maximum cutting speed of $v_{c}=1,200 \mathrm{~m} / \mathrm{min}$. In addition to abrasive wear, material adhesions occur. In addition to 
SEM microscopy, the worn tool is investigated using energy-dispersive X-ray microscopy (EDX) to assess material adhesion. The dominant adhesion elements found on the tool are manganese $(\mathrm{Mn})$, sulfur $(\mathrm{S})$, and iron $(\mathrm{Fe})$, which are all found in the workpiece material of grey cast iron EN-GJL-250. As an example, the element detections for $\mathrm{Mn}$ and Fe are shown in Fig. 6.
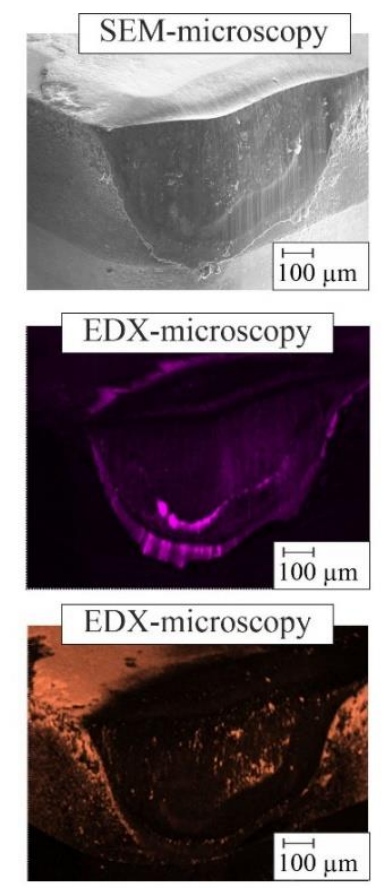

$\mathrm{v}_{\mathrm{c}}=600 \mathrm{~m} / \mathrm{min}$


EDX-microscopy

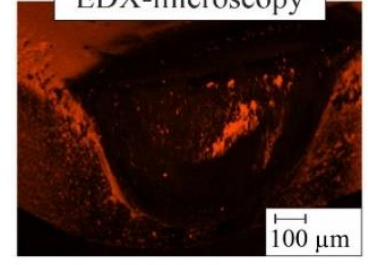

$\mathrm{v}_{\mathrm{c}}=900 \mathrm{~m} / \mathrm{min}$ Cutting speed

\begin{tabular}{ll}
\hline Workpiece & Tool \\
Cylinder liner & CBN-indexable insert \\
Drill $=130 \mathrm{~mm}$ & $\mathrm{r}_{\varepsilon}=0.4 \mathrm{~mm}$ \\
Grey cast iron & $\mathrm{S}_{\alpha}=\mathrm{S}_{\gamma}=15 \mu \mathrm{m}, \alpha=7^{\circ}$ \\
EN-GJL-250 & chamfer face
\end{tabular}
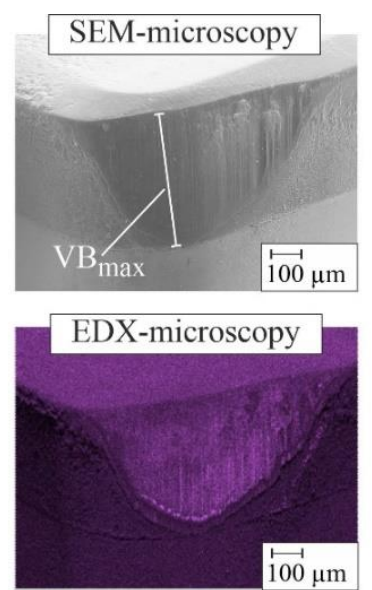

EDX-microscopy

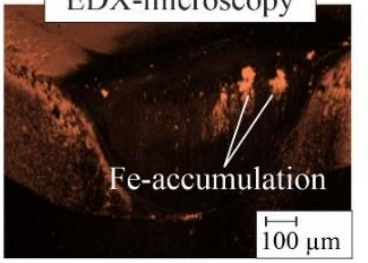

$\mathrm{v}_{\mathrm{c}}=1,200 \mathrm{~m} / \mathrm{min}$

$\begin{array}{ll}\text { Process } & \text { Process parameters } \\ \text { Internal longitudinal } & \mathrm{v}_{\mathrm{c}}=600 ; 900 ; 1,200 \mathrm{~m} / \mathrm{min} \\ \text { turning, } & \mathrm{a}_{\mathrm{p}}=0.50 \mathrm{~mm} \\ \text { dry machining } & \mathrm{f}=0.25 \mathrm{~mm}\end{array}$

Fig. 6. Wear of CBN-cutting inserts

Manganese and sulfur are known for building up a MnS-layer on the cutting tool during dry machining of grey cast iron EN-GJL-250. This layer is protective against abrasive wear and shows a dependency on the cutting speed [18]. It can be found in the EDX-measurements shown in Fig. 6. In tools used with low cutting speed, MnS-accumulations are spread over the flank face. They are found in areas with reduced abrasive wear. However, their concentration decreases with increased cutting speed. This supports the conclusion made above that increased cutting speed decreases the tool life, since the protective MnS-layer occurs only at low cutting speed. At the highest cutting speed of $v_{c}=1,200 \mathrm{~m} / \mathrm{min}$, the layer is removed due to the higher temperature and pressure in the contact zone. Another effect of higher temperatures due to the increased cutting speed is the accumulation of Fe-adhesions on the flank face originating from the workpiece material. Although adhesions are expected to occur at lower cutting speeds, they might be a result due to tribochemical reactions between tool and workpiece. The adhesions are shown in Fig. 6 in the EDX-microscopy. These 
particles are capable of pulling out tool material particles when they are pulled off the flank face surface. In addition to the abrasive flank wear and the thermal load, this could increase the tool wear and shows that a cutting speed of $v_{c}=1,200 \mathrm{~m} / \mathrm{min}$ is not suitable for this process.

The influence of the cutting tool wear on the process forces is investigated next. The cutting edge's changed geometry can be recognized in the process forces, especially in the passive force $F_{p}$. The passive force rises from $F_{p \text {,new }}=90 \mathrm{~N}$ (new cutting edge) to up to $F_{p \text {,worn }}=450 \mathrm{~N}$ (worn cutting edge) at a cutting speed of $v_{c}=900 \mathrm{~m} / \mathrm{min}$ and a depth of cut of $a_{p}=0.5 \mathrm{~mm}$. This effect occurs for all three investigated cutting speeds. The worn tool shows higher passive forces which would be expected to lead to an increasing displacement between the tool and the workpiece.

To evaluate the process behavior during non-circular machining the process is also investigated concerning its process forces to detect interfering vibrations or interruption in the contact between tool and workpiece. The force curves shown in Fig. 7 result from an oval non-circular turning process with different cutting speeds $v_{c}=600 ; 900 \mathrm{~m} / \mathrm{min}$ and a depth of cut deviation of $a_{p}=0-50 \mu \mathrm{m}$. The cutting forces are much lower than in rough machining and decrease with increasing cutting speed. The investigations show that it is possible to adapt the depth of cut so that during one workpiece rotation the depth of cut is reduced to zero by the deflection of the piezo actuators. No disturbing vibrations or cut interruptions can be found. This allows a defined workpiece geometry to be machined.
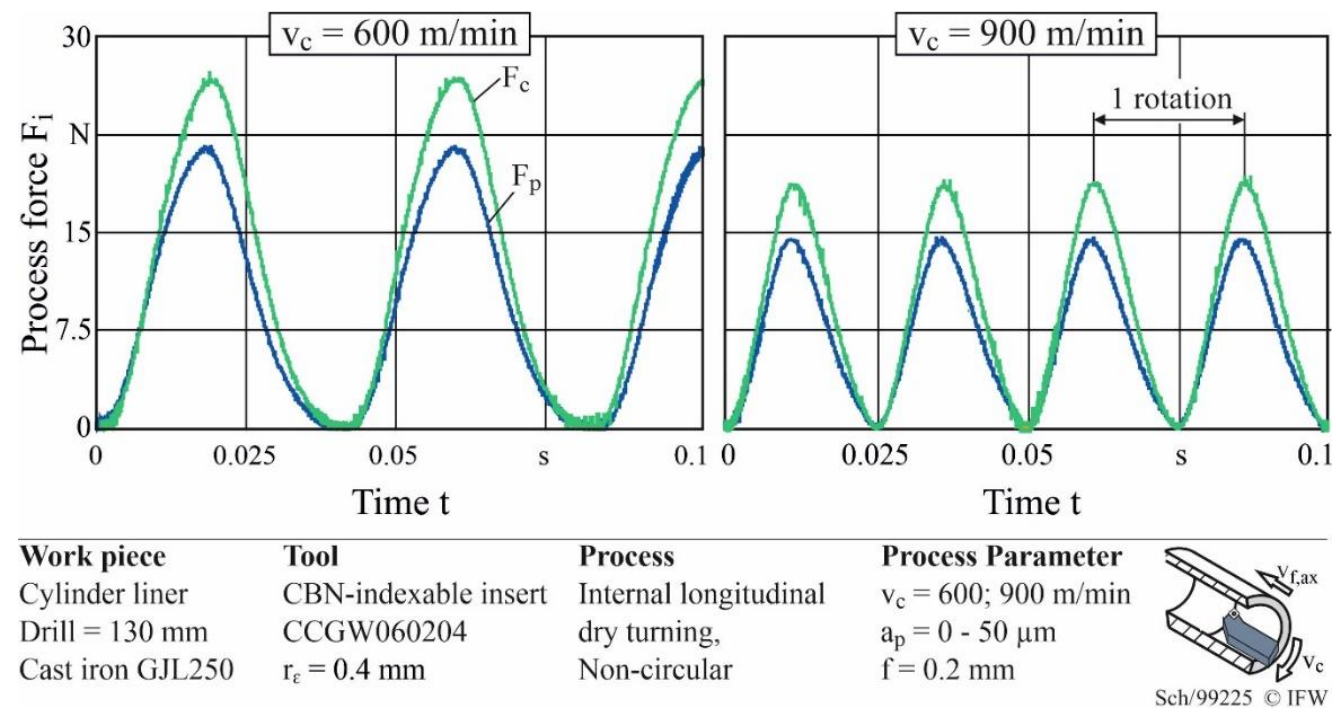

Fig. 7. Course of the process forces during non-circular turning at different cutting speeds $\mathrm{v}_{\mathrm{c}}$

In addition to the process forces and the tool wear the workpiece topography is an important evaluation factor for the process quality as the roughness after turning determines the necessary number of subsequent honing operations. This influences the productivity of the process chain. In Fig. 8, the resulting roughness after circular turning is given with the $R z$-values compared to the theoretically roughness $R_{t h}$ that is calculated from the process parameters feed $f$ and cutting edge radius $r_{\varepsilon}$. The resulting workpiece roughness shows 
a dependency on the process parameters and does not match the theoretical roughness $R_{t h}$. The deviation between measured roughness $R z$ and theoretical roughness $R_{t h}$ results from cutting edge chipping and surface defects on the workpiece. The surface defects mostly result from tearing out material from the pearlitic matrix when graphite lamellae are cut. The resulting roughness is most significantly affected by the feed, as can be expected from the geometric relationships. In contrast, no significant influence of the cutting speed $v_{c}$ on the resulting workpiece roughness can be detected. This can be explained by the partly brittle properties of the workpiece material due to the graphite lamellae within the pearlitic workpiece matrix. The material separation occurs mainly along the graphite lamellae which shows no dependency on the cutting speed and the resulting contact zone temperature. It can be stated that the surface topography is affected by the process parameters of which the feed is the main influence factor. The depth of cut $a_{p}$ and the cutting speed $v_{c}$ do not have a significant influence.
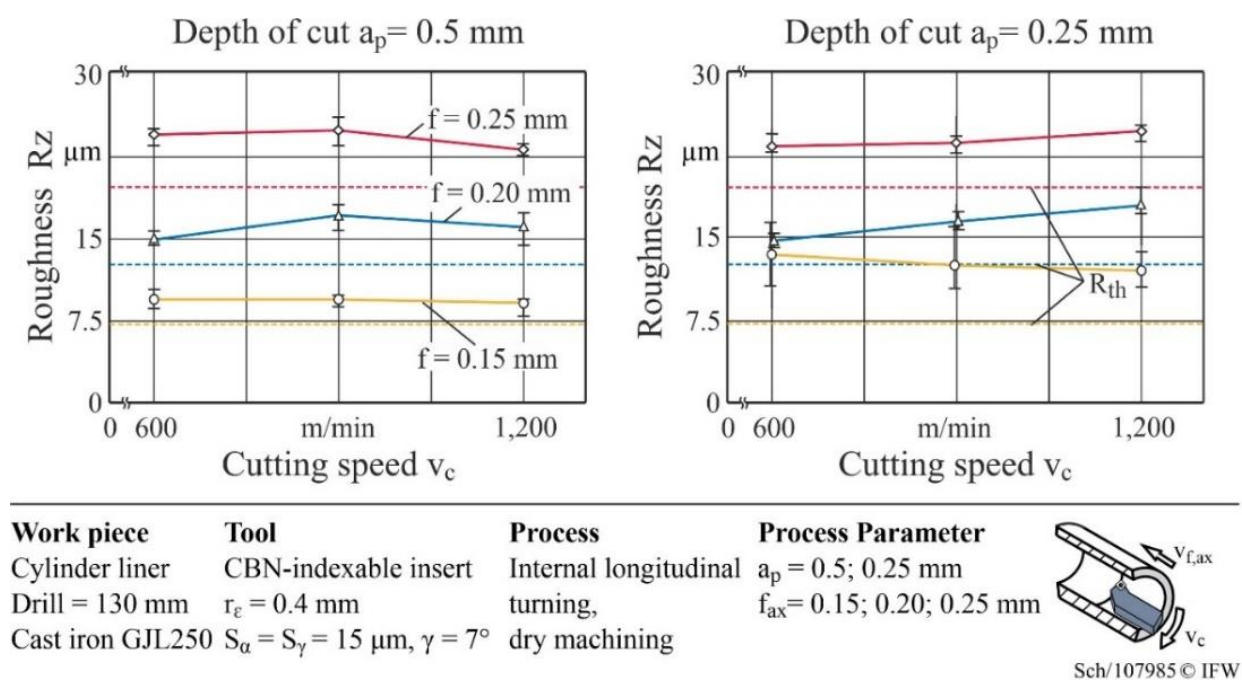

\begin{tabular}{|c|c|c|c|}
\hline $\begin{array}{l}\text { Work piece } \\
\text { Cylinder liner } \\
\text { Drill = } 130 \mathrm{~mm} \\
\text { Cast iron GJL250 }\end{array}$ & $\begin{array}{l}\text { Tool } \\
\text { CBN-indexable insert } \\
\mathrm{r}_{\varepsilon}=0.4 \mathrm{~mm} \\
\mathrm{~S}_{\alpha}=\mathrm{S}_{\gamma}=15 \mu \mathrm{m}, \gamma=7^{\circ}\end{array}$ & $\begin{array}{l}\text { Process } \\
\text { Internal longitudinal } \\
\text { turning, } \\
\text { dry machining }\end{array}$ & $\begin{array}{l}\text { Process Parameter } \\
a_{p}=0.5 ; 0.25 \mathrm{~mm} \\
f_{a x}=0.15 ; 0.20 ; 0.25 \mathrm{~mm}\end{array}$ \\
\hline
\end{tabular}

Fig. 8. Surface axial roughness depending on the process parameters

With the presented results concerning the process behavior and the resulting surface quality, the process is capable of machining cylinder liners with a defined geometry and a low deviation in surface roughness. Specific surface roughness as low as $R z=10 \mu \mathrm{m}$ can be machined with high process reliability. The next step will be to investigate whether the subsequent rough honing operation can be omitted due to the smooth turned surface. This would shorten the process chain and enhance the process chain's resource consumption.

\section{CONTROLLED FREE-FORM TURNING}

To ensure the turning of adaptable free-forms as shown in Fig. 2, the control of the hybrid tool must also be designed to be flexible. The general structure is shown in Fig. 9. To achieve precise, repeatable insertion of the free-form depending on angle and height, axis information can be read from the machine control by synchronous action and be transmitted 
via Profibus. The $Z$-axis position which correlates with the height of the cylinder liner is updated by the machine control every $12 \mathrm{~ms}$ due to the limitation of the IPO-cycle which leads to a sampling frequency of $83 \mathrm{~Hz}$. Also, the spindle angle is required, which correlates with the polar angle of the cylinder liner.

Taking into account the Nyquist-Shannon sampling theorem, only spindle speeds up to 2,500 1/min can be displayed when reading the spindle angle from the machine control with a sampling frequency of $83 \mathrm{~Hz}$. For the intended cutting speeds of up to $1,200 \mathrm{~m} / \mathrm{min}$ for the microstructuring process higher spindle speeds of up to 3,000 1/min and thus a sampling frequency of at least $100 \mathrm{~Hz}$ are required. Therefore, an additional signal splitter was installed in the machine, which uses the encoder signal before the machine control and makes it available to the Beckhoff-IPC, so that a sampling frequency of the spindle angle of $1 \mathrm{kHz}$ is obtained.

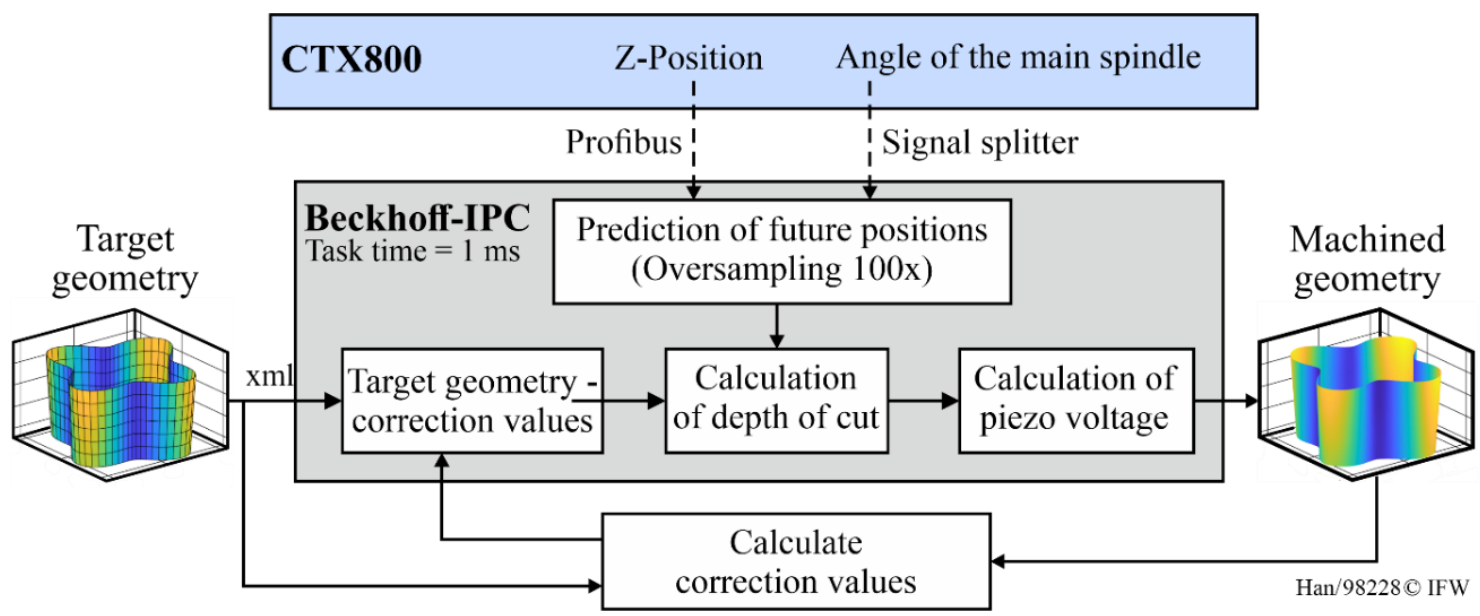

Fig. 9. Schematic overview of the piezo control

To gain a smooth sinusoidal shape and to avoid quantization errors for a structuring frequency of $2 \mathrm{kHz}$, the actuating frequency of the piezo actuators should be as high as possible. An actuating frequency of $100 \mathrm{kHz}$ and a resolution of 16 Bit are used. With this, a sinus wave with a frequency of $2 \mathrm{kHz}$ has 50 actuating values and a maximum quantization error of $15 \mathrm{mV}$ over the entire input voltage range of the piezo actuator. As the actuating values need to be already calculated at the beginning of each task cycle, they need to be predicted for the next axis positions. Using the target geometry, the depth of cut of the next task cycles can be calculated by prediction of the $Z$-axis positions and the spindle angle based on the measured axis speeds. With the depths of cut of the next task cycle, the next actuating voltage of the piezo actuator is calculated based on the modeled piezo characteristic.

After the process, the cylinder liner geometry is measured with the confocal sensor of the hybrid tool. The measured signal is filtered and a machined geometry is calculated. This machined geometry is compared with the target geometry at defined grid positions and correction values for these positions are determined. Between these positions, the correction values are interpolated. When producing the next cylinder liner these corrections of the geometry can be considered to compensate production errors, e.g. tool deflection. With this, 
a process control and an autonomous adaption of the piezo actuator stroke are realized that reduce the scrap rate in the process chain and thus increase the energy efficiency.

Figure 10 shows the first results of the free-form turning process. In Fig. 10a, the target geometry is illustrated. It is a sinusoidal test-form with amplitude decreasing with the height of the cylinder liner. This geometry was chosen because it has a higher complexity in the circumferential direction than the deviations of the cylinder liner in the combustion engine which exact shape is to be determined in the progress of the project. Figure 10b shows the machined geometry. The aimed free-form geometry can successfully be machined into the cylinder liner. Figure 10c shows the production error of the process obtained by subtracting the machined deviation from the target deviation. The maximum error is $10 \mu \mathrm{m}$. The mostly negative radial errors show that not enough material was removed in the process. The production error results from the displacement of the cylinder liner during the process and the hysteresis of the piezo actuator. Both effects occur depending on the target geometry. To reduce these errors, they can either be modeled to adapt the target geometry, or the radial error can be used as a correction value in the process control.
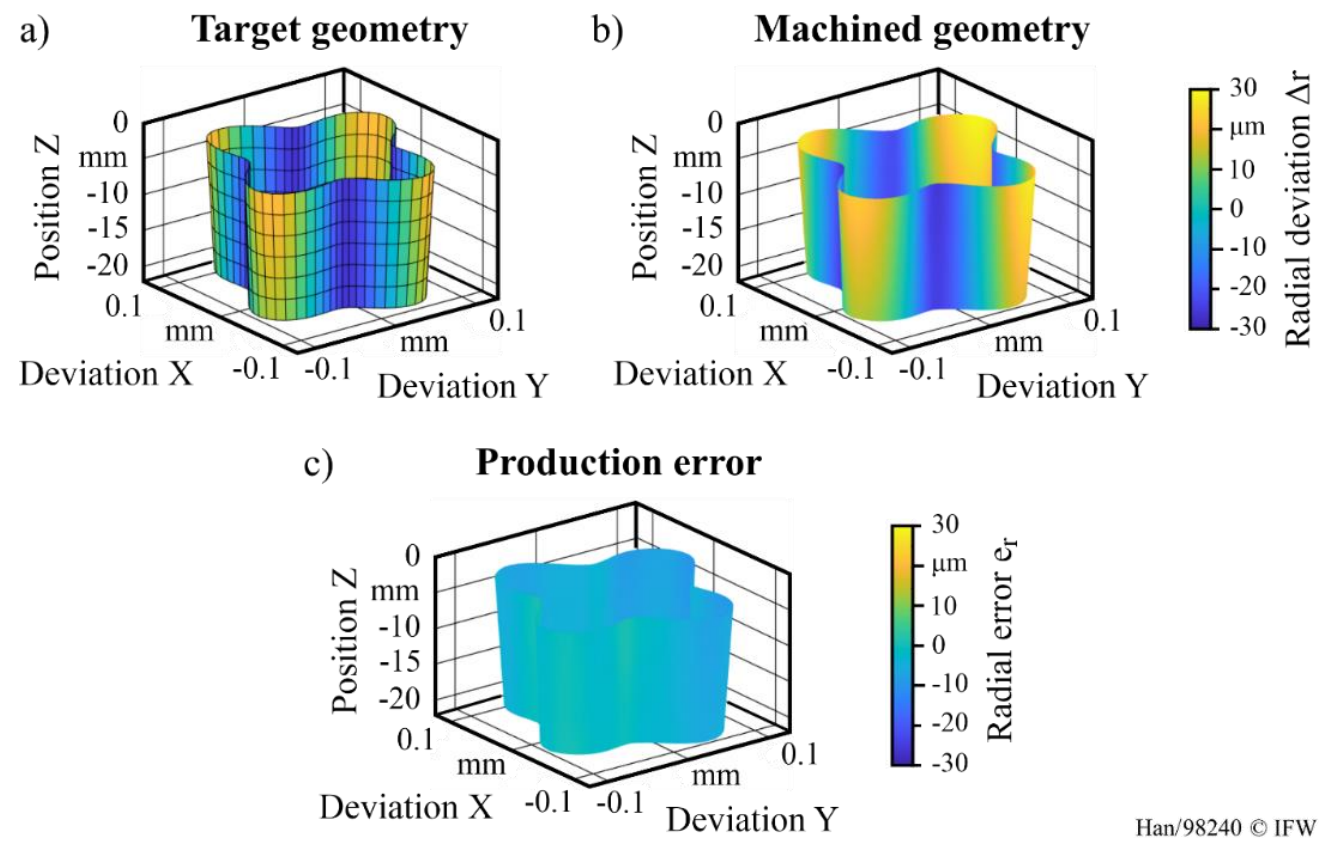

Han/98240 @ IFW

Fig. 10. a) target geometry, b) machined geometry, c) production error

\section{CONCLUSION AND OUTLOOK}

In this paper, a new hybrid tool capable of performing a non-circular turning process and a micro structuring process is shown. Using this tool, the process chain for the production of cylinder liners can be shortened by replacing a rough honing step which increases the energy efficiency of the process chain. For the use of the hybrid tool in series production, the wear behavior in dry machining of grey cast iron cylinder liners and its influence on the process forces and the surface roughness were investigated. Investigations of the surface 
show a low deviation in the surface roughness despite varying depths of cut in the circumferential direction which enables the non-circular turning process to substitute rough and form honing processes. The hybrid tool has an adaptable control system that can be used for the non-circular turning of free-forms. Production errors can be monitored by an installed optical distance sensor. Thereby, the process can be adapted by correcting the target geometry. Thus, the hybrid tool is suitable for the automation of the process chain and ensures a reduced scrap rate.

In the future, the non-circular turning process will be combined with the micro structuring process. The associated challenge will be that the micro structuring cutting insert needs to follow the non-circular turned geometry to guarantee a constant maximum depth of cut. Subsequently, the friction reduction of non-circular turned and microstructured cylinder liners will be investigated on a Floating Liner engine test bench. Parallel to this, the new process chain will be evaluated regarding its energy consumption. The new type of manufactured cylinder liners will then be compared with cylinder liners manufactured according to the state of the art in terms of their energy demand in the production and during their service life.

\section{ACKNOWLEDGEMENTS}

The results presented in this paper were obtained within the research project "Powertrain 2025". The authors would like to thank the Federal Ministry of Economics and Energy (BMWi) for financing the project (funding code: 03ET1531A) and our project partners Gühring KG, DMG MORI GmbH and the Institute for Technical Combustion (ITV) from Leibniz University Hannover.

\section{REFERENCES}

[1] INTERNATIONAL ORGANIZATION OF MOTOR VEHICLE MANUFACTURERS, 2019, Passenger Cars in Use, http://www.oica.net/wp-content/uploads//PC_Vehicles-in-use.pdf, (called on Aug 2020).

[2] UNITED NATIONS, 2016, Paris Agreement, https://treaties.un.org/doc/Treaties/2016/02/20160215\%200603\%20PM/Ch_XXVII-7-d.pdf (called on Jun 2021).

[3] STATISTA INC, 2020, Passenger Car Sales in Selected European Countries in 1st Quarter 2020, by Fuel Type, https://www.statista.com/statistics/500546/share-of-fuel-types-of-passenger-car-fleet-in-europe-by-country/, (called on Nov 2020).

[4] JEDRZEJEWSKI J., KWASNY W., 2011, Study on Reducing Energy Consumption in Manufacturing Systems, Journal of Machine Engineering, 11/3, 7-19.

[5] HOFFMEISTER H.W., 2019, Honing, CIRP Encyclopedia of Production Engineering, Springer-Verlag, Berlin, Heidelberg.

[6] GRZESIK W., 2016, Influence of Surface Textures Produced by Finishing Operations on Their Functional Properties, Journal of Machine Engineering, 16/1, 15-23.

[7] KHADEM M., OLEKSIY V., YANG H.K., KIM D.E., 2017, Tribology of Multilayer Coatings for Wear Reduction: A review, Friction, 5, 248-262.

[8] DENKENA B., KÄSTNER J., GÖTTSCHING T., 2014, Microstructuring by Means of Cutting Processes, Microstructuring of Thermo-Mechanically Highly Stressed Surfaces, Final Report of the DFG Research Group 576, Springer Verlag, 28-58.

[9] DAHLMANN D., DENKENA B., 2017, Hybrid Tool for High Performance Structuring and Honing of Cylinder liners, CIRP Annals, 66, 113-116.

[10] MAO B., SIDDAIAH A., LIAO Y., MENEZES P., 2020, Laser Surface Texturing and Related Techniques for Enhancing Tribological Performance of Engineering Materials: A review, Journal of Manufacturing Processes, 53, 153-173. 
[11] JIAO R., NGUYEN V., LE V., BUI V., 2020, Optimal Design of Micro-Dimples on Crankpin Bearing Surface for Improving Engine's Lubrication and Friction, Industrial Lubrication and Tribology, 73/1, 52-59.

[12] DENKENA B., KÖHLER J., KÄSTNER J., GÖTTSCHING T., et al., 2013, Efficient Machining of Microdimples for Friction Reduction, Journal of Micro and Nano-Manufacturing, 1, 011003, 1-8.

[13] DENKENA B., GROVE T., SCHMIDT C., 2018, Machining of Micro Dimples for Friction Reduction in Cylinder Liners, Procedia CIRP, 78/3 18-322.

[14] DROEDER K., HOFFMEISTER H.-W., GROSSE T., 2017, Force-Controlled form Honing Using a PiezoHydraulic form Honing System, CIRP Annals, 66, 317-320.

[15] FLORES G., WIENS A., LAHRES M., HOFFMEISTER H.W., 2011, Form Honing, ATZ Produktion Worldwide eMagazine, 4, 20-25.

[16] DROSSEL W.G., HOCHMUTH C., SCHNEIDER R., 2013, An Adaptronic System to Control Shape and Surface of Liner Bores During the Honing Process, CIRP Annals - Manufacturing Technology, 6, 331-334.

[17] BRECHER C., SCHAUERTE G., MERZ M., 2008, Model Based Control of a Piezo-Actuated Axis, Mitsuishi M., Ueda K., Kimura F. (eds), Manufacturing Systems and Technologies for the New Frontier, Springer, London.

[18] SOUSA J.A., SALES W.F., MACHANDO A.R., 2018, A Review on the Machining of Cast Irons, International Journal of Advanced Manufacturing Technology, 94, 4.073-4.092. 